\title{
PENGARUH SELF EFFICACY TERHADAP PELAKSANAAN DETEKSI DINI KANKER SERVIKS METODE IVA DI KOTA KEDIRI
}

\author{
Eko Winarti ${ }^{1}$, Fauzia Laili $^{2}$ \\ ${ }^{1,2}$ D IV Kebidanan, Fakultas Ilmu Kesehatan, Universitas Kadiri \\ ekowinarti@unik-kediri.ac.id
}

\begin{abstract}
The purpose of the study is to determine the relationship between self-efficacy and the implementation of VIA (Visual Inspection with Acetic Acid) cancer early detection of cervical cancer in Puskesmas Kediri City. This research was conducted on unpregnant married woman on Kediri in 2016 who met the criteria: 1) a group of case, namely some women who were married, unpregnant and had carried out early detection of cervical cancer IVA method; 2) Control group, that is, some women who have been married, are unpregnant but have not implemented the early detection of cervical cancer in the IVA method. The subjects in this study are 410 peoples which were divided into case groups of 205people and control groups of 205 people. The data collection used a questionnaire. Based on the results of research data analysis using logistic regression statistical tests obtained OR values: 3.3 (95\% CI 2.1 - 5.2) with a significance level of 0.001. So it can be concluded that women who have big perceived self efficacy have an opportunity 3.3 times greater for conducting IVA examinations compared with women who are perceived less capable of self efficacy.
\end{abstract}

Keywords: self efficacy, Early detection of cervical cancer, IVA examination

\begin{abstract}
ABSTRAK
Penelitian ini bertujuan untuk mengetahui pengaruh self-efficacy terhadap pelaksanaan deteksi dini kanker serviks metode IVA (Inspeksi Visual Asam Asetat) di Puskesmas Kota Kediri. Penelitian ini dilakukan pada Wanita yang sudah menikah dan tidak sedang hamil di Kota Kediri tahun 2016 yang memenuhi kriteria: 1) kelompok case yaitu sebagian wanita yang telah menikah, tidak sedang hamil dan telah melaksanakan deteksi dini kanker serviks metode IVA; 2) Kelompok kontrol yaitu sebagian wanita yang telah menikah, tidak sedang hamil tetapi belum melaksanakan deteksi dini kanker serviks metode IVA. Jumlah subyek penelitian sebanyak 410responden yang terbagi menjadi kelompok case 205 responden dan kelompok kontrol 205 responden. Alat pengumpul data yang digunakan adalah kuesioner. Berdasarkan hasil analisis data penelitian dengan menggunakan uji statistik regresi logistik diperoleh nilai OR: 3,3 (95\% CI 2,1 - 5,2) dengan taraf signifikansi 0,001 . Maka dapat disimpulkan bahwa wanita yang mempunyai perceived self efficacy sangat mampu mempunyai peluang 3,3 kali lebih besar untuk melakukan pemeriksaan IVA dibandingkan dengan wanita yang perceived self efficacy kurang mampu.
\end{abstract}

Kata Kunci: Self efficacy, Deteksi dini kanker serviks, Pemeriksaan IVA 


\section{PENDAHULUAN}

Kanker adalah merupakan salah satu penyakit penyebab kematian utama di seluruh dunia termasuk di Indonesia. Di Indonesia pada tahun 2013, kanker serviks dan payudara meruoakan penyakit yang menduduki prevalensi tertinggi di Indonesia yaitu sebesar 0,8\% (kanker serviks) dan kanker payudara sebesar 0,5\% (Kementerian Kesehatan RI, 2015). Deteksi dini kanker serviks dan segera diberikan pengobatan terbukti efektif untuk menurunkan morbiditas dan mortalitas kanker serviks, tetapi rata-rata kunjungan deteksi dini di Negara berkembang masih jauh dari yang diharapkan (Jia et al., 2013; Donnelly, 2006). WHO menjelaskan bahwa saat ini penyakit kanker serviks menduduki peringkat kedua diantara semua jenis kanker dan menyebabkan kematian pada wanita di dunia, serta $85 \%$ terjadi pada wanita di Negara berkembang (Jia et al., 2013;Jaspers et al., 2011). Kanker serviks sebenarnya penyakit yang dapat dicegah dan dapat diobati jika diketahui sejak awal (McGee, 2015).

Berdasarkan data dari Globocan, International Agency for Research on Cancer (IARC) menunjukkan bahwa prevalensi kanker serviks secara global mencapai 16 per 100.000 wanita (Wahidin, 2015). Berdasarkan Globocan 2012 di tahun 2012 terdapat 528.000 kasus kanker serviks di dunia (McGee, 2015). Indonesia merupakan Negara dengan kasus kanker serviks terbanyak kedua setelah Negara Cina (Irawati, 2012). Di Indonesia, setiap tahun diperkirakan 13.762 wanita didiagnosis terkena kanker serviks dan 7.493 mengalami kematian. Kanker serviks di Indonesia juga menempati peringkat kedua dari segi jumlah penderita kanker pada wanita setelah kanker payudara (Jaspers et al., 2011).

Berdasarkan estimasi jumlah penderita kanker serviks dan kanker payudara terbanyak terdapat pada Provinsi Jawa Timur dan Provinsi Jawa Tengah (Kementerian Kesehatan RI, 2015). Di Indonesia pada umumnya pasien kanker serviks yang berobat ke rumah sakit telah dalam stadium lanjut, yaitu: stadium IA dan IIA tercatat $28,6 \%$, stadium IIB sampai IVB yang datang ke rumah sakit sebanyak 66,4\% dan Program atau kegiatan deteksi dini yang dilakukan pada masyarakat hanya akan berhasil apabila kegiatannya dihubungkan dengan pengobatan yang adekuat, terjangkau, aman dan mampu dilaksanakan serta mencakup $80 \%$ populasi perempuan yang berisiko. Agar dapat mengurangi jumlah perempuan yang tidak mendapat tindak lanjut penatalaksanaan setelah deteksi dini, diupayakan pengobatan segera dengan menggunakan pendekatan komprehensif. Pendekatan komprehensif atau dengan istilah dilihat dan diobati (see and treat) untuk pencegahan kanker leher Rahim yaitu melalui kunjungan sekali yaitu mengaitkan IVA dengan pengobatan krioterapi (Kementerian Kesehatan Republik Indonesia, 2015). Stadium IIIB tercatat $37,7 \%$ (Khosidah dan Trisnawati, 2015).

Cakupan pelaksanaan deteksi dini kanker serviks metode IVA di Indonesia masih rendah yaitu $2,45 \%$, sehingga memerlukan upaya lebih kuat untuk mencapai target, yaitu deteksi dini 50\% wanita usia 30-50 tahun selama 5 tahun (Wahidin, 2015). Pelaksanaan deteksi dini kanker serviks metode IVA di Kota Kediri masih rendah yaitu kurang dari satu persen dari target Dinas Kesehatan Kota Kediri yang ditetapkan 10\% (Winarti, et al., 2017). Fenomena rendahnya perilaku deteksi dini kanker serviks dapat mengakibatkan meningkatnya angka kesakitan dan kematian penderita kanker serviks di Indonesia. Seseorang yang mengalami kanker serviks akan mengalami dampak pada kehidupan pribadinya dan keluarganya. Selain itu, kejadian kanker serviks ini akan berdampak pada sektor pembiayaan kesehatan pemerintah (Komite Penanggulangan Kanker Nasional, 2015). Fogg Behavior Model (FBM) atau model perilaku menurut Fogg juga disebutkan bahwa perilaku manusia terjadi karena tiga factor yaitu: motivasi, kemampuan (ability)/self efficacy dan pemicu (trigger). FBM juga menegaskan bahwa seseorang mau melakukan perilaku sasaran jika dia memiliki: 1) Motivasi yang cukup, 2) Kemampuan yang cukup untuk melakukan efektif perilaku, dan 3) Pemicu yang atau dipicu untuk melakukan perilaku (Fogg, 2009). Berbeda dengan kanker payudara di mana deteksi dini dapat dilakukan sendiri sehingga edukasi dari kelompok sebaya dapat bermanfaat (Purnani dan Binti, 2018), kanker serviks membutuhkan peningkatan selfefficacy agar perempuan mau memeriksakan dirinya ke layanan kesehatan. Berdasarkan latar belakang tersebut diatas peneliti tertarik meneliti hubungan antara self-efficacy dengan pelaksanaan deteksi dini kanker serviks metode IVA di Puskesmas Kota Kediri. 


\section{METODE PENELITIAN}

Variabel dalam penelitian ini adalah self efficacy dan pelaksanaan deteksi dini kanker serviks metode IVA. Self efficacy alam penelitian ini adalah jawaban respon den tentang kemampuan dirinya untuk melaksanakan deteksi dini kanker serviks. Variabel ini diukur dengan menggunakan kuesioner yang telah diuji validitas dan reliabilitas. Sedangkan variabel pelaksanaan deteksi dini kanker serviks metode IVA dalam penelitian ini adalah bentuk tindakan yang dilakukan responden berupa pelaksanaan deteksi dini kanker servik, diukur dengan lembar observasi. Sampel penelitian ini sebanyak 410 responden yang terbagi menjadi kelompok case 205 orang dan kelompok kontrol 205 orang. Penelitian ini dilakukan pada Wanita yang sudah menikah dan tidak sedang hamil di Kota Kediri tahun 2016 yang memenuhi kriteria: 1) kelompok case yaitu sebagian wanita yang telah menikah, tidak sedang hamil dan telah melaksanakan deteksi dini kanker serviks metode IVA; 2) Kelompok kontrol yaitu sebagian wanita yang telah menikah, tidak sedang hamil tetapi belum melaksanakan deteksi dini kanker serviks metode IVA. Alat pengumpul data yang digunakan adalah kuesioner. Uji validitas telah dilaksanakan di Puskesmas Wilayah Kerja Kota Kediri dengan jumlah responden 32 orang. Berdasarkan hasil uji validitas terhadap instrumen penelitian diperoleh bahwa seluruh indikator pada kuesioner ini dianggap mampu mengukur variabel dalam penelitian ini, karena nilai probabilitas seluruh pertanyaan $<0,05$ dan nilai probabilitas 0,774 . Teknik analisis data yang digunakan dalam penelitian ini adalah tehnik komparasi, dengan menggunakan uji regresi logistik dengan bantuan program komputer.

\section{HASIL}

Responden penelitian yang digunakan sebanyak 410 responden yang terbagi menjadi kelompok case terdiri 205 orang dan kelompok control terdiri 205 orang. Responden dipilih secara acak atau random dari wanita usia $20-$ 50 tahun yang memenuhi kriteria dengan berbagai macam latar belakang baik pendidikan, pekerjaaan, budaya dan sebagainya. Karakteristik responden baik pada kelompok yang melaksanakan pemeriksaan IVA maupun kelompok yang tidak melaksanakan pemeriksaan IVA. Pada kelompok yang melaksanakan pemeriksaan IVA dan yang tidak melaksanakan pemeriksaan IVA diketahui usia responden saat penelitian sebagian besar berusia $\geq 35$ tahun yakni $68,3 \%$ dan $53,7 \%$. Status pernikahan responden pada kelompok yang melaksanakan pemeriksaan IVA maupun pada kelompok yang tidak melaksanakan pemeriksaan IVA hampir seluruhnya juga menikah yakni $98,0 \%$ dan 95,6\%. Pendidikan responden baik kelompok yang melaksanakan pemeriksaan IVA maupun kelompok yang tidak melaksanakan pemeriksaan IVA hampir separuhnya adalah pendidikan menengah (SMA sederajat) yakni 50,2\% dan 47,8. Kelompok yang melaksanakan pemeriksaan IVA dan kelompok yang tidak melaksanakan pemeriksaan IVA, pekerjaan responden sebagian besar adalah ibu rumah tangga yakni $78,0 \%$ dan $62,9 \%$. Pelaksanan deteksi dini Kanker Serviks menurut perceived self eficacy sebagai berikut.

Tabel 1. Distribusi Frekuensi Variabel Perceived Self Efficacy dengan Pelaksanaan Deteksi Dini Kanker Serviks Di Puskesmas Wilayah Kerja Dinas Kesehatan Kota Kediri

\begin{tabular}{|l|l|l|l|}
\hline \multicolumn{1}{|c|}{ Variabel } & \multicolumn{1}{|c|}{ Kategori } & \multicolumn{1}{c|}{ Frekuensi } & \multicolumn{1}{c|}{ Persentase (\%) } \\
\hline Perceived Self Efficacy & Kurang Mampu & 114 & 27,8 \\
\hline $\begin{array}{l}\text { Pelaksanaan Deteksi Dini } \\
\text { Kanker Serviks Metode IVA }\end{array}$ & Sangat Mampu & 296 & 72,3 \\
\hline & Tidak & 205 & 50 \\
\hline
\end{tabular}


Tabel 2.Hubungan Perceived Self Efficacy dengan Pelaksanaan Deteksi Dini Kanker Serviks di Puskesmas Wilayah KerjaDinasKesehatan Kota Kediri

\begin{tabular}{|c|c|c|c|c|c|c|c|c|c|}
\hline \multirow[t]{3}{*}{ Variabel } & \multirow[t]{3}{*}{ Kategori } & \multicolumn{4}{|c|}{ PelaksanaanPemeriksaan IVA } & \multirow{2}{*}{\multicolumn{2}{|c|}{ Total }} & \multirow{3}{*}{$\begin{array}{c}\text { Nilai } \\
\text { OR }\end{array}$} & \multirow{3}{*}{$\begin{array}{c}\text { CI } \\
95 \%\end{array}$} \\
\hline & & \multicolumn{2}{|c|}{ Ya } & \multicolumn{2}{|c|}{ Tidak } & & & & \\
\hline & & $\mathrm{n}$ & $\%$ & $\mathrm{n}$ & $\%$ & $\mathrm{n}$ & $\%$ & & \\
\hline \multirow{2}{*}{$\begin{array}{l}\text { Perceived } \\
\text { self } \\
\text { efficacy }\end{array}$} & $\begin{array}{l}\text { Kurangm } \\
\text { ampu }\end{array}$ & 34 & 29,8 & 80 & 70,2 & 114 & 100 & $R e f$ & \\
\hline & $\begin{array}{l}\text { Sangat } \\
\text { mampu }\end{array}$ & 171 & 57,8 & 125 & 42,2 & 296 & 100 & 3,3 & $\begin{array}{r}2,1- \\
5,2\end{array}$ \\
\hline
\end{tabular}

Keterangan: ${ }^{* *}: p$ value <0.01 (signifikan), CI: Confidence Interval

Tabel 1 menunjukkan bahwa sebagaian besar responden mempunyai perceived self efficacy dalam kategori sangat mampu. Berdasarkan tabel 2, dapat diketahui hasil analisis bivariabel antara perceived self efficacy dengan pelaksanaan IVA menunjukkan bahwa perceived self efficacy secara statistik memiliki hubungan yang bermakna dengan pelaksanaan IVA. Dilihat dari hasil analisis didapatkan OR: 3,3 (95\% CI $2,1-5,2)$ pada perceived self efficacy sangat mampu, hal ini dapat disimpulkan bahwa wanita yang mempunyai perceived self efficacy sangat mampu mempunyai peluang 3,3 kali lebih besar untuk melakukan pemeriksaan IVA dibandingkan dengan wanita yang perceived self efficacy kurang mampu.

\section{PEMBAHASAN}

Efikasi diri (self efficacy) mengacu pada keyakinan sejauh mana individu memperkirakan kemampuan dirinya untuk mampu mengerjakan suatu tugas atau kewajiban yang bertujuan untuk mencapai hasil tertentu. Keyakinan akan seluruh kemampuan diri diantaranya memiliki kepercayaan diri, mampu menyesuaikan diri dengan lingkungan sekitar, serta memiliki kapasitas kognitif, kecerdasan dan kapasitas bertindak pada situasi yang penuh tekanan. Kepercayaan pada kemampuan diri seseorang untuk mempengaruhi perubahan dalam hasil (self efficacy) adalah kunci dari perubahan perilaku kesehatan (Onoruoiza et al., 2015). Self efficacy diri yang dimiliki seseorang dapat digunakan dalam memprediksi perilaku sehat dan dapat memfasilitasi modifikasi perilaku seseorang. Orang lebih cenderung mengadopsi perilaku kesehatan jika mereka berfikir mereka akan berhasil. Menurut (Bandura, 1994) self efficacy alam ditumbuhkan dan dipelajari melalui empat hal yaitu: pengalaman menguasai sesuatu, modeling sosial, persuasi sosial, kondisi fisik dan emosional. Tinggi rendahnya efficacy diri sesorang dalam tiap tugas sangat bervariasi. Hal ini disebabkan oleh adanya beberapa faktor yang berpengaruh dalam mempersepsikan kemampuan diri individu. Ada bebeberapa yang memengaruhi efficacy diri antara lain: budaya, jenis kelamin, sifat dari tugas yang dihadapi, intensi feksternal, status atau peran individu dalam lingkungan, informasi tentang kemampuan diri (Bandura, 1994). Faktor yang memengaruhi self efficacy yaitu pengalaman langsung dan pengalaman tidak langsung (Yansen Gultom, 2015).

Dchwarzer \& Renner (2000) menyebutkan tiga prediktor utama yang memengaruhi niat seseorang adalah persepsi risiko, harapan outcome dan coping self efficacy. Dchwarzer \& Renner (2000) menyebutkan Individu yang mempunyai self efficacy baik akan mempunyai perilaku nutrisi yang baik. Niat merupakan prediktor utama untuk merubah perilaku.Niat dan coping self efficacy memengaruhi diet rendah lemak dan tinggi serat.

Self efficacy berkorelasi penting dengan kepatuhan meskipun tidak secara langsung dipengaruhi oleh dukungan sosial. Mungkin variabel lain seperti motivasi lebih berdampak langsung terhadap niat (Winarti et al., 2018).

Hal ini sesuai dengan Fogg Behavior Model (2009) yang disebutkan bahwa perilaku manusia terjadi karena tiga factor yaitu: motivasi, ability dan pemicu (trigger. Dengan demikian hasil penelitian ini sesuai dengan hasil penelitian terdahulu dan menguatkan teori yang ada. 


\section{KESIMPULAN}

Kesimpulan yang didapat dari penelitian ini adalah terdapat pengaruh self efficacy terhadap pelaksanaan deteksi dini kanker serviks menggunakan metode IVA di Puskesmas Kota Kediri. Semakin seorang wanita merasa dirinya mampu melaksanakan pemeriksaan IVA maka wanita tersebut akan semakin melaksanakan pemeriksaan deteksi dini kanker serviks metode IVA

\section{SARAN}

Berdasarkan hasil penelitian terdapat hubungan antara self efficacy dengan pelaksanaan deteksi dini kanker serviks metode IVA di Kota Kediri, sehingga diharapkan kepada pengambil kebijakan di Kota Kediri untuk mengembangkan program pendidikan pendidikan kesehatan tentang deteksi dini kanker serviks yang dapat meningkatkan self efficacy seorang wanita. Cara untuk meningkatkan self efficacy pada wanita dalam melaksanakan deteksi dini kanker serviks metode IVA yaitu : 1) Melakukan pendidikan kesehatan dengan cara melibatkan wanita yang sudah pernah atau rutin melaksanakan pemeriksaan IVA ; 2) Mengikutsertakan suami dalam proses penyuluhan dan 3) Pemutaran film tentang kanker serviks dan upaya pencegahannya.

\section{DAFTAR PUSTAKA}

Bandura, A. 1994. Self-Efficacy. Encyclopedia of human behavior, 4(1994), pp. 71-81. doi: 10.1002/9780470479216.corpsy0836.

Dchwarzer \& Renner. 2000. Social-cognitive predictors of health behavior: action selfefficacy and coping self-efficacy. National Center for Biotechnology Information, 19(5).

Donnelly, T. T. 2006. The Health-Care Practices of Vietnamese-Canadian Women: Cultural Influences on Breast.

Fogg, B. J. 2009. A Behavior Model for Persuasive Design.

Irawati, B. 2012. Regression ( GPR ) dan Regresi Binomial Negatif. 2(2), pp. 1324.

Jaspers, L. et al. 2011. Parental acceptance of human papillomavirus ( HPV ) vaccination in Indonesia: A crosssectional study. Vaccine. Elsevier Ltd, 29(44), pp. 7785-7793. doi: 10.1016/j.vaccine.2011.07.107.

Jia, Y. et al. 2013. Knowledge about Cervical
Cancer and Barriers of Screening Program among Women in Wufeng County, a High-Incidence Region of Cervical Cancer in China. 8(7), pp. 2-9. doi: 10.1371/journal.pone.0067005.

Kementerian Kesehatan Republik Indonesia. 2015. Peraturan Menteri Kesehatan Republik Indonesia. Jakarta: Kementerian Kesehatan RI.

Kementerian Kesehatan RI. 2015. Stop Kanker. Jakarta Selatan: Kementerian Kesehatan RI.

Khosidah, A. dan Trisnawati, Y. 2015. Faktor yang mempengaruhi ibu rumah tangga dalam melakukan TES IVA sebagai upaya deteksi dini kanker serviks. Jurnal ilmiah Kebidanan, 6(2), pp. 94-105.

Komite Penanggulangan Kanker Nasional. 2015. Panduan Penatalaksanaan Kanker Serviks. Jakarta: Kementerian Kesehatan RI.

McGee, P. 2015. Cervical Cancer, 12(Supplement 2), pp. 77-80. doi: 10.1093/annonc/mds193.

Onoruoiza, S. I. et al. 2015. Using Health Beliefs Model as an Intervention to Non Compliance with Hypertension Information among Hypertensive Patient. International Organization of Scientific Research Journal of Humanities And Social Science, 20(9), pp. 11-16. doi: 10.9790/0837-20951116.

Wahidin, M. 2015. Deteksi dini kanker leher rahim dan kanker payudara di Indonesia 2007-2014. Buletin jendela dan data informasi kesehatan, 1(1), pp. 12-15.

Purnani, Weni Tri dan Binti Qoni'ah. 2018. Efektivitas Pendidikan Kesehatan Metode Peer Group Education Dengan Metode Demonstrasi Terhadap Keterampilan Sadari. Journal of Public Health Research and Community Health Development, 2(1), pp. 54-60.

Winarti, E., Santoso, B. dan Hargono, R. 2017. Psychosocial Factors are Associated with Participation in Cervical Cancer Screening Programs: A Structural Equations Model. 7(10), pp. 32-39.

Winarti, E., Santoso, B. dan Hargono, R. 2018. Health Notions, Volume 2 Number 4 ( April 2018 ) Trigger, Self Efficacy and Motivation in The Implementation of Cervical Cancer Screening 494 | Publisher: Humanistic Network for Science and Technology Health Notions . 
2(4), pp. 494-499.

Yansen Gultom. 2015. Pengaruh Pengetahuan,

Pengalaman spesifik, dan Self Efficacy

Terhadap Kinerja...', VI(01), pp. 36-53. 